\title{
Correlation and path analysis studies for yield and quality traits in tomato (Solanum lycopersicum $\mathbf{L}$.)
}

\author{
B. Rajasekhar Reddy ${ }^{1}$, Mula Pratapa Reddy ${ }^{2}$, D. Siddeswar Reddy ${ }^{3}$, \\ Hameedunnisa Begum ${ }^{4}$ \\ ${ }^{I} P G$ Student, College of Horticulture, DrYSRHU, Rajendranagar, Hyderabad-30 ${ }^{2}$ Research Scholar, Department of \\ Genetics and Plant Breeding, BHU, Varanasi ${ }^{3}$ PG Student, College of Agriculture, DrPDKV, Akola ${ }^{4}$ Principal Scientist, \\ Vegetable Research Station, DrYSRHU, Rajendranagar, Hyderabad-30.
}

\begin{abstract}
Correlation and path analysis were carried out in nineteen tomato genotypes for yield and quality characters. The association studies showed that fruit yield per plant was positively and significantly correlated with number of fruits per plant and fruit width. However, fruit yield per plant was negatively and significantly correlated with days to last fruit harvest and shelf life. Path analysis studies done to study the cause and effect relationship revealed that plant height, number of fruits per plant, fruit length, fruit width and ascorbic acid had high positive direct effects on fruit yield per plant. Hence, direct selection for these traits is done for improving fruit yield per plant.
\end{abstract}

Key words: Correlation and Path analysis, Tomato, Genotypes, Yield and quality

\section{Introduction}

Tomato (Solanum lycopersicum L.) is a member of the family solanaceae and significant vegetable crop of special economic importance in the horticultural industry worldwide (He et al., 2003). It has a chromosome number of $2 n=24$. Tomato is a native of Peru Equador region (Rick, 1969). It is the most important warm-season fruit vegetable grown throughout the world. Tomato is the most important vegetable crop next only to potato because of its wider adaptability, high yielding potential and multipurpose uses. Tomatoes are consumed as fresh and in processed form. In India, tomato occupies an area of 0.60 million hectares with a production of 11.15 million tonnes and productivity of 18.61 tonnes per hectare (FAO, 2009). Tomato is grown as a annual or short lived perennial herbaceous plants. It has taproot and growth habit of the plant is determinate, semideterminate and indeterminate.

Yield is a complex character and selection for yield and yield components deserves considerable attention. A crop breeding programme, aimed at increasing the plant productivity requires consideration not only of yield but also of its components that have direct or indirect bearing on yield. Correlation and path coefficient analysis give an insight into the genetic variability present in populations. Correlation coefficient analysis measures the mutual relationship between various plant characters and determines the component characters on which selection can be based for improvement in yield. Path analysis splits the correlation coefficients into direct and indirect effects of a set of dependent variables on the independent variable thereby aids in selection of elite genotype.

An improvement in yield and quality in self pollinated crop like tomato is normally achieved by selecting the genotypes with desirable character combinations existing in nature or by hybridization. Information on the nature and extent of variability present in genetic stocks, heritability, genetic advance and interrelationship among various characters is a prerequisite for framing any selection program.

\section{Materials And Methods}

Nineteen genotypes of tomato consisting of sixteen exotic collections and three varieties were evaluated in an augmented block design at National Bureau of Plant Genetic Resources (NBPGR) Regional Station, Hyderabad. The experiment laid out in eight blocks. In each block two genotypes of exotic collection and three varieties i.e., ArkaVikas, Marutham and Punjab Chhauhara which are used as checks are planted at a spacing of $60 \times 50 \mathrm{~cm}$ in a single row. Due to limited germplasm of each genotype the experiment is laid out of augmented block design. Observations were recorded for eighteen qualitative and quantitative characters viz., Plant height $(\mathrm{cm})$, number of primary branches, days to $50 \%$ flowering, number of clusters per plant, number of flowers per clusters, days to first fruit set, days to first fruit harvest, days to last fruit harvest, number of fruits per clusters, number of fruits per plant, fruit length $(\mathrm{cm})$, fruit width $(\mathrm{cm})$, fruit weight, fruit yield per plant $(\mathrm{kg})$, ascorbic acid (mg/100g), acidity (\%), TSS ( ${ }^{\circ}$ Brix) and shelf life (days). 


\section{Results And Discussion}

Simple correlation studies were carried for all the characters studied. Number of fruits per plant and fruit width had significant positive correlation with fruit yield per plant. Days to last fruit harvest and shelf life had significant negative relationship with fruit yield per plant. The results are in accordance with Kumar et al. (2006), Dhankhar and Dhankar (2006) for number of fruits per plant, Singh et al, (2007) and Singh (2009) for fruit width. Number of primary branches per plant and number of flowers per cluster had significantly positive correlation with plant height. Similar results are also observed by Prashanth et al. (2008). Number of fruits per cluster and ascorbic acid had significantly positive association with number of primary branches per plant and days to $50 \%$ flowering and days to last fruit harvest had negative association with number of primary branches per plant. Results are in accordance with Kumar and Dudi (2011).

Days to first fruit set, days to first fruit harvest and shelf life had positive association with days to $50 \%$ flowering. Number of clusters per plant had positive association with number of fruits per plant and TSS and negative association with days to first fruit harvest and shelf life. Results are in accordance with Kumar and Dudi (2011) for number of clusters per plant and number of fruits per cluster. Number of flowers per cluster had positive association with number of fruits per cluster. Days to first fruit set had positive association with days to first fruit harvest and shelf life. Days to first fruit harvest had positive association with shelf life. Days to last fruit harvest had negative association with TSS. Number of fruits per plant had negative correlation with acidity. Fruit length had highly significant positive correlation with fruit weight and TSS. Fruit width had highly significant positive correlation with fruit weight. Fruit weight had negative correlation with TSS. Ascorbic acid had negative association with TSS. Acidity had positive association with TSS. Results are in accordance with Kumar and Dudi (2011) for fruit weight, TSS, acidity.

The path coefficient studies (Table 2) revealed that plant height, number of fruits per plant, fruit length, fruit width and ascorbic acid had high positive direct effects on fruit yield per plant, shelf life had moderate direct positive effects on fruit yield per plant. High negative direct effects on fruit yield per plant had been observed for number of primary branches per plant, days to $50 \%$ flowering, number of clusters per plant, number of flowers per cluster, days to first fruit set, days to first fruit harvest and fruit weight. The results are in accordance with the findings of Asati et al. (2008) for plant height, number of primary branches per plant, days to 50\% flowering and fruit weight, Kumar and Thakur (2007) for number of fruits per plant, fruit length and fruit width, Mayavel et al. (2005) for number of primary branches per plant.

\section{Conclusion}

The association and cause effect studies showed that fruit yield per plant was positively and significantly correlated with number of fruits per plant and fruit width. High direct effects are also observe for these traits. So, by improving these traits yield can be significantly increased.

Table 1: Correlation coefficients between different quantitative and qualitative characters of tomato

\begin{tabular}{|c|c|c|c|c|c|c|c|c|c|}
\hline & 1 & 2 & 3 & 4 & 5 & 6 & 7 & 8 & 9 \\
\hline 1 & 1.0000 & $0.7185^{* * *}$ & -0.1782 & 0.2982 & $0.5137 *$ & -0.268 & 0.0921 & -0.3679 & 0.3001 \\
\hline 2 & & 1.0000 & $\begin{array}{c}- \\
0.4670^{*} \\
\end{array}$ & $\begin{array}{c}- \\
0.1074 \\
\end{array}$ & 0.3906 & -0.3727 & 0.0909 & $\begin{array}{c}- \\
0.5342 *\end{array}$ & $0.5140^{*}$ \\
\hline 3 & & & 1.0000 & $\begin{array}{c}- \\
0.3918 \\
\end{array}$ & -0.235 & $0.9063^{* * *}$ & $0.5730^{*}$ & 0.2997 & -0.2192 \\
\hline 4 & & & & 1.0000 & 0.1962 & -0.3525 & $0.5848^{* *}$ & -0.1254 & 0.3036 \\
\hline 5 & & & & & 1.0000 & -0.3099 & -0.1322 & -0.4498 & $0.4725^{*}$ \\
\hline 6 & & & & & & 1.0000 & $0.6254 * *$ & 0.3302 & -0.0673 \\
\hline 7 & & & & & & & 1.0000 & 0.0486 & -0.0262 \\
\hline 8 & & & & & & & & 1.0000 & -0.3621 \\
\hline 9 & & & & & & & & & 1.0000 \\
\hline 10 & & & & & & & & & \\
\hline 11 & & & & & & & & & \\
\hline 12 & & & & & & & & & \\
\hline 13 & & & & & & & & & \\
\hline 14 & & & & & & & & & \\
\hline 15 & & & & & & & & & \\
\hline 16 & & & & & & & & & \\
\hline 17 & & & & & & & & & \\
\hline 18 & & & & & & & & & \\
\hline
\end{tabular}


Table 1. Conti....

\begin{tabular}{|c|c|c|c|c|c|c|c|c|c|}
\hline & $\mathbf{1 0}$ & $\mathbf{1 1}$ & $\mathbf{1 2}$ & $\mathbf{1 3}$ & $\mathbf{1 4}$ & $\mathbf{1 5}$ & $\mathbf{1 6}$ & $\mathbf{1 7}$ & $\mathbf{1 8}$ \\
\hline 1 & -0.2427 & -0.1422 & -0.06 & -0.1271 & 0.0549 & 0.3872 & 0.3443 & -0.155 & 0.0598 \\
\hline 2 & 0.0576 & -0.036 & 0.0278 & -0.0818 & $0.4642^{*}$ & 0.1134 & 0.2159 & -0.3619 & 0.2319 \\
\hline 3 & 0.0216 & 0.1504 & 0.2437 & 0.3266 & -0.2395 & 0.1355 & 0.2122 & $0.6122^{* *}$ & -0.264 \\
\hline 4 & $0.4799^{*}$ & -0.2313 & -0.0271 & -0.2244 & 0.1379 & -0.1773 & -0.146 & $-0.5241^{*}$ & 0.3642 \\
\hline 5 & 0.1589 & -0.0036 & 0.2671 & 0.2206 & 0.2746 & 0.0751 & 0.0679 & -0.342 & 0.388 \\
\hline 6 & 0.0895 & 0.098 & 0.149 & 0.1913 & -0.1533 & 0.1426 & 0.2693 & $0.6613^{* *}$ & -0.3952 \\
\hline 7 & -0.1321 & 0.332 & 0.301 & 0.3471 & 0.0726 & 0.1536 & 0.1905 & $0.4884^{*}$ & -0.0934 \\
\hline 8 & -0.4193 & -0.0525 & -0.1175 & -0.0972 & -0.4214 & 0.1705 & -0.1445 & 0.4207 & $-0.5357 *$ \\
\hline 9 & 0.3727 & -0.0357 & 0.0535 & -0.0564 & 0.1355 & -0.2476 & 0.0366 & -0.0745 & 0.0127 \\
\hline 10 & $\mathbf{1 . 0 0 0 0}$ & 0.049 & 0.1844 & 0.0885 & 0.0601 & $-0.4589 *$ & -0.1827 & -0.0784 & $0.5324^{*}$ \\
\hline 11 & & $\mathbf{1 . 0 0 0 0}$ & 0.37 & $0.7113^{* * *}$ & -0.0148 & -0.3795 & $0.6206^{* *}$ & 0.0305 & 0.3052 \\
\hline 12 & & & $\mathbf{1 . 0 0 0 0}$ & $0.8683^{* * *}$ & -0.1059 & -0.0828 & -0.3552 & -0.2263 & $0.4807^{*}$ \\
\hline 13 & & & & $\mathbf{1 . 0 0 0 0}$ & -0.0735 & -0.1639 & $-0.4697 *$ & -0.0587 & 0.3936 \\
\hline 14 & & & & & $\mathbf{1 . 0 0 0 0}$ & 0.0567 & 0.3484 & -0.3353 & 0.2262 \\
\hline 15 & & & & & & $\mathbf{1 . 0 0 0 0}$ & $0.6416^{* *}$ & 0.0663 & -0.34 \\
\hline 16 & & & & & & & $\mathbf{1 . 0 0 0 0}$ & 0.1589 & -0.4098 \\
\hline 17 & & & & & & & & $\mathbf{1 . 0 0 0 0}$ & $-0.5336^{*}$ \\
\hline 18 & & & & & & & & & $\mathbf{1 . 0 0 0 0}$ \\
\hline
\end{tabular}

Table 2: Direct and indirect effects of different qualitative and quantitative characters on yield in tomato

\begin{tabular}{|c|c|c|c|c|c|c|c|c|c|}
\hline & $\mathbf{1}$ & $\mathbf{2}$ & $\mathbf{3}$ & $\mathbf{4}$ & $\mathbf{5}$ & $\mathbf{6}$ & $\mathbf{7}$ & $\mathbf{8}$ & $\mathbf{9}$ \\
\hline 1 & $\mathbf{1 . 2 2 2 3}$ & 0.8782 & -0.2178 & -0.3645 & 0.6279 & -0.3276 & 0.1126 & -0.4496 & 0.3668 \\
\hline 2 & -1.1059 & $\mathbf{- 1 . 5 3 9 1}$ & 0.7188 & 0.1653 & -0.6012 & 0.5737 & -0.1399 & 0.8221 & -0.7911 \\
\hline 3 & 0.0502 & 0.1315 & $\mathbf{- 0 . 2 8 1 6}$ & 0.1103 & 0.0662 & -0.2553 & -0.1614 & -0.0844 & 0.0617 \\
\hline 4 & 0.1213 & 0.0437 & 0.1593 & $\mathbf{- 0 . 4 0 6 7}$ & -0.0798 & 0.1434 & 0.2378 & 0.051 & -0.1235 \\
\hline 5 & -0.1793 & -0.1364 & 0.082 & -0.0685 & $\mathbf{- 0 . 3 4 9 1}$ & 0.1082 & 0.0461 & 0.157 & -0.1649 \\
\hline 6 & 0.1918 & 0.2667 & -0.6486 & 0.2523 & 0.2218 & $\mathbf{- 0 . 7 1 5 7}$ & -0.4476 & -0.2363 & 0.0482 \\
\hline 7 & -0.0146 & -0.0144 & -0.0905 & 0.0924 & 0.0209 & -0.0988 & $\mathbf{- 0 . 1 5 7 9}$ & -0.0077 & 0.0041 \\
\hline 8 & -0.0201 & -0.0291 & 0.0164 & -0.0068 & -0.0245 & 0.018 & 0.0027 & $\mathbf{0 . 0 5 4 6}$ & -0.0198 \\
\hline 9 & -0.0046 & -0.0078 & 0.0033 & -0.0046 & -0.0072 & 0.001 & 0.0004 & 0.0055 & $\mathbf{- 0 . 0 1 5 2}$ \\
\hline 10 & -0.2345 & 0.0556 & 0.0209 & 0.4637 & 0.1535 & 0.0865 & -0.1277 & -0.4052 & 0.3602 \\
\hline 11 & -0.1565 & -0.0397 & 0.1656 & -0.2547 & -0.0039 & 0.1079 & 0.3656 & -0.0578 & -0.0393 \\
\hline 12 & -0.1324 & 0.0614 & 0.5377 & -0.0597 & 0.5891 & 0.3287 & 0.6641 & -0.2592 & 0.1181 \\
\hline 13 & 0.2502 & 0.1609 & -0.6428 & 0.4415 & -0.4341 & -0.3764 & -0.6831 & 0.1913 & 0.111 \\
\hline 14 & 0.0539 & 0.4557 & -0.2351 & 0.1353 & 0.2696 & -0.1505 & 0.0713 & -0.4136 & 0.133 \\
\hline 15 & 0.0355 & 0.0104 & 0.0124 & -0.0162 & 0.0069 & 0.0131 & 0.0141 & 0.0156 & -0.0227 \\
\hline 16 & 0.0146 & 0.0092 & 0.009 & -0.0062 & 0.0029 & 0.0114 & 0.0081 & -0.0061 & 0.0016 \\
\hline 17 & -0.0321 & -0.075 & 0.1269 & -0.1086 & -0.0709 & 0.1371 & 0.1013 & 0.0872 & -0.0154 \\
\hline 18 & $\mathbf{0 . 0 5 9 8}$ & $\mathbf{0 . 2 3 1 9}$ & $\mathbf{- 0 . 2 6 4}$ & $\mathbf{0 . 3 6 4 2}$ & $\mathbf{0 . 3 8 8}$ & $\mathbf{- 0 . 3 9 5 2}$ & $\mathbf{- 0 . 0 9 3 4}$ & $\mathbf{- 0 . 5 3 5 7}$ & $\mathbf{0 . 0 1 2 7}$ \\
\hline
\end{tabular}


Table 2. Conti...

\begin{tabular}{|c|c|c|c|c|c|c|c|c|}
\hline & $\mathbf{1 0}$ & $\mathbf{1 1}$ & $\mathbf{1 2}$ & $\mathbf{1 3}$ & $\mathbf{1 4}$ & $\mathbf{1 5}$ & $\mathbf{1 6}$ & $\mathbf{1 7}$ \\
\hline 1 & -0.2966 & -0.1738 & -0.0734 & -0.1554 & 0.0671 & 0.4732 & 0.4209 & -0.1894 \\
\hline 2 & -0.0886 & 0.0555 & -0.0428 & 0.1259 & -0.7145 & -0.1745 & -0.3323 & 0.557 \\
\hline 3 & -0.0061 & -0.0424 & -0.0686 & -0.092 & 0.0675 & -0.0382 & -0.0598 & -0.1724 \\
\hline 4 & -0.1952 & 0.0941 & 0.011 & 0.0912 & -0.0561 & 0.0721 & 0.0594 & 0.2131 \\
\hline 5 & -0.0555 & 0.0012 & -0.0932 & -0.077 & -0.0959 & -0.0262 & -0.0237 & 0.1194 \\
\hline 6 & -0.0641 & -0.0701 & -0.1066 & -0.1369 & 0.1097 & -0.102 & -0.1927 & -0.4733 \\
\hline 7 & 0.0209 & -0.0524 & -0.0475 & -0.0548 & -0.0115 & -0.0243 & -0.0301 & -0.0771 \\
\hline 8 & -0.0229 & -0.0029 & -0.0064 & -0.0053 & -0.023 & 0.0093 & -0.0079 & 0.023 \\
\hline 9 & -0.0057 & 0.0005 & -0.0008 & 0.0009 & -0.0021 & 0.0038 & -0.0006 & 0.0011 \\
\hline 10 & $\mathbf{0 . 9 6 6 4}$ & 0.0473 & 0.1782 & 0.0855 & 0.0581 & -0.4435 & -0.1766 & -0.0758 \\
\hline 11 & 0.0539 & $\mathbf{1 . 1 0 1 1}$ & 0.4073 & 0.7832 & -0.0162 & -0.4179 & -0.6834 & 0.0336 \\
\hline 12 & 0.4068 & 0.8161 & $\mathbf{2 . 2 0 6}$ & 1.9155 & -0.2336 & -0.1827 & -0.7835 & -0.4991 \\
\hline 13 & -0.1741 & -1.3998 & -1.7089 & $\mathbf{- 1 . 9 6 8}$ & 0.1446 & 0.3226 & 0.9243 & 0.1154 \\
\hline 14 & 0.059 & -0.0145 & -0.1039 & -0.0721 & $\mathbf{0 . 9 8 1 6}$ & 0.0556 & 0.342 & -0.3291 \\
\hline 15 & -0.042 & -0.0348 & -0.0076 & -0.015 & 0.0052 & $\mathbf{0 . 0 9 1 6}$ & 0.0588 & 0.0061 \\
\hline 16 & -0.0078 & -0.0264 & -0.0151 & -0.0199 & 0.0148 & 0.0272 & $\mathbf{0 . 0 4 2 5}$ & 0.0067 \\
\hline 17 & -0.0163 & 0.0063 & -0.0469 & -0.0122 & -0.0695 & 0.0137 & 0.0329 & $\mathbf{0 . 2 0 7 3}$ \\
\hline 18 & $\mathbf{0 . 5 3 2 4}$ & $\mathbf{0 . 3 0 5 2}$ & $\mathbf{0 . 4 8 0 7}$ & $\mathbf{0 . 3 9 3 6}$ & $\mathbf{0 . 2 2 6 2}$ & $\mathbf{- 0 . 3 4}$ & $\mathbf{- 0 . 4 0 9 8}$ & $\mathbf{- 0 . 5 3 3 6}$ \\
\hline R square $=0.9744 ;$ Residual effect $=0.1599$ & & & & & \\
\hline
\end{tabular}

1. Plant Height (cm); 2. Number of primary branches per plant;3. Days to $50 \%$ flowering; 4 . Number of clusters per plant; 5 . Number of flowers per cluster; 6. Days to first fruit set; 7. Days to first fruit harvest; 8. Days to last fruit harvest 9. Number of fruits per cluster; 10. Number of fruits per plant; 11. Fruit length $(\mathrm{cm}) ; 12$. Fruit width $(\mathrm{cm}) ; 13$. Fruit weight $(\mathrm{g}) ; 14$. Ascorbic acid (mg/100g); 15. Acidity (\%); 16. TSS (oBrix); 17. Shelf life (Days); 18. Fruit yield per plant (kg)

\section{Acknowledgements}

I am thankful to College of Horticulture, Dr.Y. S. R. Horticultural University, Rajendranagar, Hyderabad and National Bureau of Plant Genetic Resources Regional Station, Hyderabad for providing the facilities for conducting my research.

\section{References}

[1]. Anonymous. 2009. FAOSTAT Database. Food and Agriculture Organisation, Rome, Italy.

[2]. Asati, B.S., Rai, N. and Singh, A.K. 2008. Genetic parameters study for yield and quality traits in tomato. The Asian Journal of Horticulture, 3(2): 222-225.

[3]. Dhankhar, S.K. and Dhankar, S.S. 2006. Variability, heritability, correlation and path coefficient studies in tomato. Haryana Journal of Hortcultural Science, 35(1\&2): 179-181.

[4]. He, C., Poysa, V. and Yu, K. 2003. Development and characterization of simple sequence repeat (SSR) markers and their use in determining relationships among Lycopersicon esculentum cultivars. Theoretical Applied Genetics, 106: 363-373.

[5]. Kumar, M. and Dudi, B.S. 2011. Study of correlation for yield and quality characters in tomato (Lycopersicon esculentum Mill.). Electronic Journal of Plant Breeding, 2(3): 453-460.

[6]. Kumar, R and Thakur, M.C. 2007. Genetic variability, heritability, genetic advance, correlation coefficient and path analy sis in tomato. Haryana Journal of Horticultural Science, 36(3 \& 4): 370-373.

[7]. Kumar, R., Niraj Kumar, Jagadeesh Singh and Rai, G.K. 2006. Studies on yield and quality traits in tomato. Vegetable Science, 33(2): 126-132.

[8]. Mayavel, A., Balakrishnamurthy, G. and Natarajan, S. 2005. Correlation and path analysis in tomato (Lycopersicon esculentum Mill). South Indian Horticulture, 53(1-6): 253-257.

[9]. Prashanth, S.J., Jaiprakashnarayan, R.P., Mulge, R. and Madalageri, M.B. 2008. Correlation and path analysis in tomato (Lycopersicon esculentum Mill.). The Asian Journal of Horticulture, 3(2): 403-408.

[10]. Singh, A.K. 2009. Genetic variability, heritability and genetic advance studies in tomato under cold arid region of Ladakh. Indian Journal of Horticulture, 66 (3): 400-403.

[12]. Singh, J., Mathura Rai, Rajesh Kumar, Prasanna, H.C., Ajay Verma Rai, G.K. and Singh, A.K. 2007. Genotypic variation and hierarchical clustering of tomato (Solanum lycopersicum) based on morphological and biochemical traits, Vegetable Science. 34(1): $40-45$. 